\title{
Oil sorption by exfoliated graphite from dilute oil-water emulsion for practical applications in produced water treatments
}

Kenji Takeuchi ${ }^{\mathrm{a}, \mathrm{b}}$, Masatsugu Fujishige ${ }^{\mathrm{a}}$, Hidenori Kitazawa ${ }^{\mathrm{b}}$, Noboru Akuzawa ${ }^{\mathrm{b}}$, Josue Ortiz Medina $^{\text {b }}$, Aaron Morelos-Gomez ${ }^{\text {b }}$, Rodolfo Cruz Silva ${ }^{\text {b }}$, Takumi Araki ${ }^{\text {b,c }}$, Takuya Hayashi a, Mauricio Terrones ${ }^{\mathrm{a}, \mathrm{d}}$ and Morinobu Endo ${ }^{\mathrm{a}, \mathrm{b}, *}$

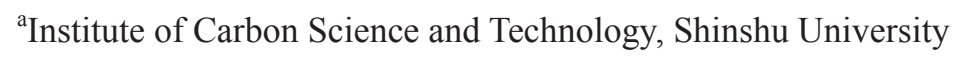

4-17-1 Wakasato, Nagano 380-8553, Japan

${ }^{\mathrm{b}}$ Global Aqua Innovation Center, Shinshu University

4-17-1 Wakasato, Nagano 380-8553, Japan

${ }^{\mathrm{c}}$ Research Organization for Information Science \& Technology, 2-32-3, Kitashinagawa, Shinagawa-ku, Tokyo 140-0001, Japan

${ }^{\mathrm{d} D e p a r t m e n t}$ of Materials Science and Engineering, Department of Chemistry, and Department of Physics, The Pennsylvania State University

University Park, Pennsylvania 16802, USA

*Corresponding Author

E-mail addresses: endo@endomoribu.shinshu-u.ac.jp (M. Endo)

Key word: oil, sorption, exfoliated graphite

\begin{abstract}
We used engine oil-water emulsion as a model produced water to evaluate the oil sorption properties of exfoliated graphite (EG) and showed that $100 \mathrm{mg} / \mathrm{L}$ of oil in emulsion can be reduced to a concentration of a 0.1 -few $\mathrm{mg} / \mathrm{L}$ using as-received commercially available $\mathrm{EG}$ and surface modified EG subjected to an additional oxidation treatment. Oil at a concentration of less than $15 \mathrm{mg} / \mathrm{L}$, as an example of oil discharged to sea, was cleared only by the EG treatment.
\end{abstract}

(C) 2015. This manuscript version is made available under the Elsevier user license http://www.elsevier.com/open-access/userlicense/1.0/ 
Although EG also sorbs water, it sorbs oil preferentially and the oil concentration of the sorbed phase in EG was estimated to be about 200 times that of the initial untreated emulsion. The sorption mechanism was discussed with the aid of the ab-initio relaxation calculation and classical molecular dynamics (MD) simulation for $\mathrm{n}$-Hexane $\left(\mathrm{C}_{6} \mathrm{H}_{14}\right)$ adsorption on graphene. When EG was incorporated with micron-size iron particles, the oil sorbed EG was found to be effectively recovered from emulsion by using magnetic field. The oil concentration in emulsion treated with EG was able to reduce down to the level comparable to that achieved by nanofiltration (NF) or reverse osmosis (RO) membrane treatment. We concluded that EG from natural graphite can effectively remove oil component during the treatment of emulsion and exhibits high potential for practical use.

\section{Introduction}

The worldwide output of conventional fossil fuel resources, especially the outputs of petroleum and gas, and the production of unconventional shale gas in association with recent engineering developments are increasing. Produced water, which is defined as the residual water that remains after oil separation and removal from the water used during the extraction of crude oil, is generated as byproduct of conventional and unconventional extraction methods. The output of produced water has been reported to be approximately three to six times of crude oil or 300 million barrels per day in 2011 [1], which represents an amount of water approximately 400 times greater than the daily consumption of Tokyo. Produced water is disposed by re-injection into wells and oil layers, or is reused for enhanced oil recovery (EOR). In offshore oil fields, it is generally sent via pipelines to ground facilities, where it is treated. Produced water contains oil, gas, and various salts and inorganic and organic matter. In particular, it generally contains 10 to $1000 \mathrm{mg} / \mathrm{L}$ as total organic carbon (TOC) substances. As a pre-treatment for membrane process three stages of oil-removal procedures are generally performed, primary oil water separation (oil $<500 \mathrm{mg} / \mathrm{L}$ ), secondary oil water separation, and 
tertiary oil water separation at the level of oil $<15$ to $30 \mathrm{mg} / \mathrm{L}$, are generally performed. If needed, advanced treatments with reverse osmosis (RO) or nanofiltration (NF) membrane separation are also performed as post-processes. Produced water is normally treated until it reaches oil concentration low enough to ensure good water quality based on the effluent standards of the site; and it is ultimately discharged to sea or injected into oil layers of the well [1]. To secure soundness of the environment of oil layers and groundwater and to minimize the environmental impact of produced water, improvements in treatment processes have been required. In such processes, the oil concentration must be reduced to a level where a RO membrane is not clogged; thus the target oil content for membrane treatment is commonly less than $10 \mathrm{mg} / \mathrm{L}$. Due to the special restrictions of platforms, offshore oil fields in particular require a more effective oil removal method. A compact and high-efficiency flocculation and magnetic separation method has been developed for this process, in order to remove oil to a concentration lower than $15 \mathrm{mg} / \mathrm{L}$ [2]. More simplified and inexpensive high-efficiency produced-water treatment technologies, including technologies for treating flow-back water, whose production volume has been increasing in association with increased shale gas extraction, are anticipated. Such technologies can help prevent environmental deterioration and enable the development of resources to achieve global sustainability.

Carbon materials have high potential for oil sorption [3-10]. Inagaki et al. reported the sorption of oil into foamed graphite or exfoliated graphite (hereafter abbreviated as EG); and their results indicated that this method is useful for oil spillage [11-17]. In order to develop an advanced water purification process based on separation membrane technology for produced water treatment, we investigated the use of foamed graphite or EG for sorption and removal of oil component in engine oil-water emulsion (a model produced water) as a primary treatment method at a stage leading to a membrane process. Because of difficulty of getting practical produced water, we used engine oil-water emulsion as a model produced water in the present investigation. In general, graphite intercalation compounds with sulfuric or nitric acid molecules 
inserted between graphite layers are formed by dipping natural graphite into concentrated acid [18]. EG powder with a very low density and a high specific surface area is produced by foaming, which is accompanied by the rapid release of the intercalate by subsequent water washing, drying, and rapid heating. The powder is then compressed into graphite sheets, which have been used as heat-resistant flexible sheets. Because the raw material of the foam is natural graphite, its cost is comparatively low.

In this study, we show the reduction of the oil concentration from several hundred $\mathrm{mg} / \mathrm{L}$ in engine oil-water emulsion to less than several $\mathrm{mg} / \mathrm{L}$ by dispersing EG within it. As noted above, Inagaki et al. found that EG is useful for the sorption of oil floating over the sea $[13,15]$. On the other hand, the present investigation aims at clarifying the sorption behavior of EG against oil-water emulsion. The emulsion is composed of very fine mixture of oil and water such as oil in water and water in oil [19]. Although EG is considered to be effective also for oil-water emulsion, it has not yet been practically confirmed. This paper aims at clarifying simply whether EG can be a candidate as a sorption material for oil-water emulsion in the produced water treatment. Commercially available EG was used for produced water treatment to reduce the oil concentration to a level where the treated produced water could be fed to a subsequent membrane separation process. We show that the present EG process is a simplified primary treatment for produced water. As a practical method for recovering EG after the sorption of oil, we investigated a method using a magnetic field to recover the EG as a feasible recovery method.

Because the need for the development of an effective method for treating the produced water is rising with the increasing production of petroleum and gas resources, the results of the present study are expected to lead to enhanced environmental protection in association with the extraction of such resources.

\section{Experimental}


The exfoliated graphite samples were characterized by scanning electron microscope (ADD SEM MODEL), powder X-ray diffraction (ADD XRD MODEL), Raman spectroscopy with a $532 \mathrm{~nm}$ laser excitation (Renishaw in Via Raman microscope) and by X-ray photo electron spectroscopy (Axis-Ultra, Kratos, UK apparatus).

Emulsion composed of synthetic engine oil (Castrol, Power $14 \mathrm{~T}$ 10W-50) and deionized water was used; we also used a mineral engine oil (Honda, Ultra G1 10W-30) to confirm the effect of the kind of the engine oil, and found out that there is no difference in the sorption behavior of EG in both cases. Fixed amounts of engine oil and deionized water (or salt water containing $3.5 \mathrm{wt} \% \mathrm{NaCl}$ in some cases) were mixed and homogenized using a magnetic stirrer (950 rpm) and a homogenizer. A prescribed amount of oil was mixed with distilled water and also salt water $(3.5 \mathrm{wt} \% \mathrm{NaCl})$ using a magnetic stirrer $(950 \mathrm{rpm})$ and a homogenizer to prepare engine oil-water (or -salt water) emulsion. A fresh engine oil-water emulsion was supplied for the sorption experiment. Table 1 shows the concentrations of engine oil-water emulsions used in the experiments. One litter of engine oil-water emulsion was poured into a glass beaker, and a fixed amount of EG was added under constant stirring. Additional sorption experiments using palm shell activated charcoal and vermiculite [20] were also carried out for comparing the sorption ability with that of the EG. The oil concentration in the emulsion was determined at prescribed time (5 times in $60 \mathrm{~min}$ ) using an oil densitometer (Horiba, OCMA-505), in which oil was extracted by a solvent and the concentration was determined by the non-dispersive infrared analysis.

In each sampling, a $50 \mathrm{ml}$ of emulsion was taken from the beaker and EG was removed by filtration. The amount of EG decreased during the sorption experiment due to sampling for the chemical analysis. At the final stage $(60 \mathrm{~min})$, the volume of emulsion and the amount of EG became about $75 \%$ of those at initial stage. However, it was confirmed from a separate experiment that there was no considerable difference in the oil concentration in the emulsion after $60 \mathrm{~min}$ of sorption even if the volume was kept constant during $60 \mathrm{~min}$ of sorption 
experiment. Thereby the oil-sorbing behavior of EG was correctly evaluated with this experimental process. Table 2 summarizes the properties of the oil-sorbing samples used in these experiments. Commercial EG from Toyo Tanso Co., Ltd. (T-1) and Chuetsu Graphite Works Co., Ltd. (C-1, C-2, and C-3) were used, and a sample (TO-1) prepared by additional oxidation treatment of T-1's foamed graphite in air $\left(450^{\circ} \mathrm{C}\right.$ for $10 \mathrm{~min}$.) was also used; thus, a total of five samples were used. The four kind of EG (T-1, C-1, C-2 and C-3) have similar physical and chemical properties.

To analyze engine oil-water emulsion sorbed in the EG samples, thermograms of the sorption materials were determined by thermogravimetry (TG) after sorption experiments. The oil-to-water ratios sorbed in the EG samples were estimated. In addition, TG analyses of pure water, pure engine oil and the engine oil-water emulsion were independently performed. In the TG experiments, an inert atmosphere was attained by flowing argon gas in the apparatus.

Magnetic EG was prepared by two kinds of methods: (1) Iron citrate was dissolved in hot water $\left(\sim 90^{\circ} \mathrm{C}\right)$, and $\mathrm{EG}$ was dipped into the solution. After the EG was taken from the solution, it was dried and heat-treated at $600^{\circ} \mathrm{C}$ under hydrogen atmosphere to form iron particles in the EG matrix. (2) Graphite-iron chloride intercalation compounds were prepared by mixing EG and iron chloride, enclosing the mixture in a glass tube under vacuum, and heat treated at $300^{\circ} \mathrm{C}$ for $24 \mathrm{hrs}$. Then the samples were heat-treated at $600^{\circ} \mathrm{C}$ under hydrogen atmosphere. The crystallite size of the iron particles was estimated from the X-ray diffractogram $(\mathrm{Cu}-\mathrm{K} \alpha)$. The magnetic properties were determined using a vibrating sample magnetometer. From a viewpoint of practical application, we investigated the possibility of using a magnetic field to collect the emulsion-sorbed magnetized EG on the wall of the beaker.

\section{Results and discussion}

\subsection{Properties of the EG used}

In general, EG is produced from natural graphite by intercalation of sulfuric acid and a 
foaming treatment involving rapid heating after water washing. Fig. 1 shows SEM images of the EG used in the present experiments. Graphite crystals foam in a long eelworm shape in the direction of the c-axis during the expansion treatment. The enlarged picture shows that the graphitic layers expand to form moderate gaps leaving exposed the inner layers of the original crystal exposed.

Fig. 2 shows an X-ray diffractogram which clearly indicates typical graphite structure of the EG; a sharp 002 diffraction line appears at $2 \theta=26.5^{\circ}$, demonstrating the presence of a crystalline structure with stacking layers of the graphene planes. The crystallite size, as determined from the full width at half maxima (FWHM) of the 002 diffraction line using the Debye-Scherrer equation, is approximately $20 \mathrm{~nm}$; given that $d_{002}=0.3354 \mathrm{~nm}$ from 002 peak, the foam sample consists of graphite units with approximately 60 graphene sheets. These EG images are consistent with the SEM results in Fig. 1.

Raman spectra revealed that the oxidation of EG has a low influence upon the structure, with a negligible change in the D-band intensity shown in Fig. S1, reflected by a small increase in the D-band to G-band intensity ratio from 0.08 to 0.09 . The chemical surface analysis made by X-Ray photoelectron spectroscopy (Fig. S2) reveals that the EG before and after oxidation exhibit the same functionalities with negligible differences, a clear $\mathrm{sp}^{2}$ hybridization peak at $284.4 \mathrm{eV}$ and C-O environment resulting in a peak at $286 \mathrm{eV}$.

\subsection{Oil-sorbing properties}

Fig. 3 shows a plot of the oil concentration in engine oil-water emulsion as a function of stirring time after $10-200 \mathrm{mg} / \mathrm{L}$ of EG was added and stirred for a prescribed time. Just after the EG was added in the emulsion, the mixture was agitated with a stirrer and the EG was dispersed evenly in the container; the oil sorption proceeded rapidly, and the oil concentration suddenly decreased to $10 \mathrm{mg} / \mathrm{L}$, i.e. one-tenth its initial concentration. Then it decreased gradually and became stable at a few $\mathrm{mg} / \mathrm{L}$ after stirring for $60 \mathrm{~min}$, the stabilization times depends on the 
amount of EG used.

Insert in Fig. 3 shows on a logarithmic scale, that the concentration of the remaining oil 60 min after the EG was added decreases according to the amount of EG used. When the amount of EG exceeded $150 \mathrm{mg}$ against $1 \mathrm{~kg}$ emulsion, the remaining oil concentration decreased to less than $1 \mathrm{mg} / \mathrm{L}$; this amount is considered to be sufficiently effective as a produced water treatment method, and it corresponds to $150 \mathrm{~g}$ per 1 ton of produced water. When $200 \mathrm{mg}$ of EG was added to $1 \mathrm{~kg}$ of produced water, the remaining oil content decreased to $0.1 \mathrm{mg} / \mathrm{L}$, or $1 / 1000$ th the initial value, which indicates enough high sorption performance.

Because the sorption behavior depends on the type of EG used, we considered that foaming properties of the EG, i.e., the differences in production methods, may affect the results. The specific amount of oil sorbed by EG is more than ten times that sorbed by vermiculite. The effect of the kind of adsorbates shown in Table 2 on the oil-sorption capacity will be discussed later. Although, in some cases, the final treatment of produced water is conducted using an NF or RO membrane, the aforementioned results indicate that primary treatment with EG can remove oil to a level where the treated produced water can be fed to a membrane separation process. In general, a larger specific surface area of EG results in less remaining oil and more sorbed oil.

Although synthetic oil was used to simulate produced water, the comparison with mineral-based engine oil (Fig. 4) shows that mineral-oil based engine oil-water emulsion tends to be sorbed better into EG. As seen in Fig. 4 the sorption data on the three mineral oils are scattered. For example, the oil content after $60 \mathrm{~min}$ of sorption is in the range from $0.7 \mathrm{mg} / \mathrm{L}$ (C) to $4 \mathrm{mg} / \mathrm{L}$ (B). The sorption of oils into porous absorbents is usually an interplay between oil viscosity, surface tension and sorbent pore size. Oils with low viscosity can be treated from the sorbent under dynamic conditions such as stirring, while oil with excessively high viscosity will not efficiently infiltrate the sorbent. However, EG characteristics seems to match well those of the oils used in this study, resulting in good performances. 
Produced water often contains sea water [21]; Fig. 5 shows the oil-sorbing function of EG in engine oil-water emulsion that contains oil in sea water (salt concentration: $3.5 \mathrm{wt} \%$ ). The performance of EG as an absorbent in sea water is similar to its performance in produced water prepared using pure water. In our case, we used kinetically stabilized emulsions, which in spite of being metastable, showed good stability on the time range of our experiments. This kind of emulsion is common in some drilling and oil transport processes. These emulsion droplets have no charge and thus the effect of salt water on the sorption behavior is rather limited.

Fig. 6 shows a comparison of the oil-sorbing functions of EG in engine oil-water emulsion with that of similar materials. According to a comparison of oil-sorbing function per equal weight, commercial EGs (T-1, C-1, C-2, C-3) exhibit better sorption speed and amount compared with activated carbon (palm trees) and vermiculite. This suggests that the enlarged space in between the graphene planes of EG is important for oil molecules to be accommodated. In other words, very small apparent density of EG (i.e. very large free volume of EG) as can be seen in Table 2 has an important role in the oil-sorption. It should be noted that vermiculite could not keep its initial granular shape after oil-sorption; it became slurry due to expansion of the matrix along with oil-sorption in its cavity. Such kind of structural modification of active carbon was not seen, though the amount of oil-sorption was less than that of vermiculite. EG (TO-1), prepared by oxidation treatment in air, sorbed oil quickly compared to untreated EG and reduced the oil concentration to less than one-fifth the initial concentration after sorption for 20 min; this material therefore provides a possibility of an effective treatment method. However, this increased performance cannot be attributed to the factors such as enhancement of the surface functional groups, structural changes, etc. because they were confirmed to be similar before and after the heat-treatment at $450^{\circ} \mathrm{C}$ in air, as mentioned above. In some cases with different kind of oil, we observed the opposite effect of the heat-treatment of EG. The sorption behavior is better for untreated EG rather than EG with heat-treatment. Although the heat-treatment of EG at $450^{\circ} \mathrm{C}$ in air has a possibility of enhancing the function of EG for oil 
sorption as is the case shown in Fig. 6, a clear picture of enhancing mechanism has not yet been drawn out at present.

In order to clarify the mechanism of the oil sorption in graphene-graphene interlayer space of EG, we performed ab-initio relaxation calculation and classical molecular dynamics (MD) simulation for $\mathrm{n}-\mathrm{Hexane}\left(\mathrm{C}_{6} \mathrm{H}_{14}\right)$ adsorption on graphene, as aliphatic oil molecule and expanded graphite models, respectively. The atom charges and adsorption energy of $\mathrm{n}$-Hexane were calculated by using the ab-initio quantum method at 6-31G** level and plane wave basis set code including van der Waals interaction, NWCHEM [22] and QUANTUM ESPRESSO [23] codes. The water/graphene interface and droplet of $\mathrm{n}$-Hexane adsorption on graphene in aqueous system were performed by classical molecular dynamics adopting the General Amber Force Field [24] and SPC/E water model and NPT ensemble keeping pressure of 1 atm, DL_POLY [25] code, considering Coulomb interactions and van der Waals interactions. The temperature was set $295 \mathrm{~K}$ in MD simulations and a periodic system was used for all calculations cases.

The adsorption state and energy, defined as the difference between total energy of post-adsorption and pre-adsorption states, is shown in Fig.7a and 7b. These results indicate that the energy gain of $\mathrm{n}$-Hexane adsorption, $0.486 \mathrm{eV}$, is considerably larger than a water molecule case, $0.141 \mathrm{eV}$, which is the reason for the strong affinity of graphene for aliphatic oils. The adsorption forces involved in n-Hexane adsorption on graphene are mainly van der Waals interactions. In aqueous systems, water molecules bond each other strongly by hydrogen bonds and exclude the non-polar n-Hexane molecules to the water/air interface. If the water/air interface is replaced by the graphene surface, the n-Hexane molecules are excluded to this region and their adsorption onto graphene is enhanced by this effect. Fig. 7c shows a MD snapshot $(\mathrm{T}=$ 1ns) of the $\mathrm{n}$-Hexane exclusion process to the water/graphene interface followed by this MD calculation, the interlayer distance between graphene was set to $4 \mathrm{~nm}$ and nine 
n-Hexane molecules were located within a 900 water molecules volume. The snapshot shows clearly that n-Hexane molecules were quickly excluded to the water/graphene interface and adsorbed onto the graphene surface.

Next, we performed a simulation where a n-Hexane cluster, as a model of a droplet, was placed within two graphene surfaces, simulating the graphitic layers of the EG. Several MD snapshots of this process are shown in Fig. 8. The initial structure consists of $45 \mathrm{n}$-Hexane molecules within a 4000 water molecules volume located between two graphene surfaces separated by $10 \mathrm{~nm}$ (Fig. 8a). After drifting in the aqueous medium, few molecules of the droplet are adsorbed on the graphene, and then the droplet quickly spreads on the graphene surface (Fig. 8b). The n-Hexane molecules are already segregated from the water molecules and adsorbed on graphene (Fig. 8c). The spreading process due to the strong van der Waals interaction between graphene and $n$-Hexane molecules takes places, minimizing the interfacial energy between $\mathrm{n}-\mathrm{Hexane}$ and water (Fig. 8 d).

Fig. 9 shows a comparison of the TG traces of a mixture of both engine oil and water, engine oil, water, EG (T-1) that sorbed a mixture of both engine oil and water (synthetic oil $200 \mathrm{mg} / \mathrm{L}$ ), and EG (T-1) that sorbed engine oil only. This comparison shows that most of the water evaporated at $100^{\circ} \mathrm{C}$, that the oil started to evaporate at approximately $190^{\circ} \mathrm{C}$, and that the evaporation was completed at approximately $400^{\circ} \mathrm{C}$. The thermal behavior of EG that sorbed only engine oil was approximately the same as engine oil alone. The weight decrease of EG that sorbed a mixture of water and $200 \mathrm{mg} / \mathrm{L}$ oil was $4.7 \%$ at the oil evaporation temperature zone. On the contrary, the corresponding weight decrease was not observed for the 200 ppm emulsion without EG as seen in Fig. 9. On the other hand, we can see a non-volatile component in high temperature region up to $1000^{\circ} \mathrm{C}$ with $7.0 \%$ of weight ratio, which is attributed to EG since the atmosphere was kept inert by argon gas during the TG experiment. Therefore, we can estimate the amount of oil sorbed in EG by dividing $4.7 \%$ by $7.0 \%$. The resulting value was 0.66 
$\mathrm{g}(\mathrm{oil}) / \mathrm{g}(\mathrm{EG})$. This value was comparable to that estimated from the data in the sorption experiment before TG measurement, where $150 \mathrm{mg}$ of EG was put in 1L of emulsion with oil concentration of $200 \mathrm{mg} / \mathrm{L}$ and the oil concentration reached $6.7 \mathrm{mg} / \mathrm{L}$ when EG sample was taken out for the TG measurement. The amount of oil sorbed by EG was estimated as 0.62 $\mathrm{g}(\mathrm{oil}) / \mathrm{g}(\mathrm{EG})$ by dividing oil amount before minus after the treatment $(200-6.7 \mathrm{mg})$ by $150 \mathrm{mg}$. Taking into account the experimental errors especially in the weighing of TG sample (emulsion-sorbed EG), it can be said that both values, 0.66 (TG) and 0.62 (sorption experiment), are in good agreement. Thus, EG is able to sorb oil selectively from dilute oil-water emulsion and reduce the oil concentration remarkably. From Fig. 9, we can also estimate the oil concentration in the sorbed phase by dividing $4.7 \%$ by $(4.7 \%+88.3 \%)$, where $88.3 \%$ corresponds to the weight decrease due to water release from the emulsion. The resulting value was $0.0505 \mathrm{~g}($ oil $) / \mathrm{g}($ emulsion $)$, corresponding to $505 \mathrm{~g} / \mathrm{L}(=50500 \mathrm{mg} / \mathrm{L})$, about 250 times that of the starting emulsion $(200 \mathrm{mg} / \mathrm{L})$. Even though these are rough estimation because of the experimental errors in the TG experiment, it can be said that the oil concentration of emulsion in the sorbed phase in EG increased at least 200 times that of the untreated emulsion $(200 \mathrm{mg} / \mathrm{L})$. Such oil-sorption capability makes this material applicable for the oil sorption from the produced water.

Based on the market price of foamed graphite, $100 \mathrm{mg} / \mathrm{L}$ of oil in produced water could be reduced to less than $1 \mathrm{mg} / \mathrm{L}$ at a material cost of $\$ 1 /$ ton. Water containing oil at a concentration of $15 \mathrm{mg} / \mathrm{L}$, which is typical of oil discharged to sea, can be cleared only efficiently by EG treatment, and it is expected that EG to be promising in this application.

\subsection{Attempt to recover magnetized EG}

In order to be a feasible separation method, a simple method to recover EG is required. One of the possible ways is collecting oil sorbed EG by a magnetic field. Several studies have been carried out for the preparation of magnetic EG [26-29]. Luftfullin et al., for example, prepared 
graphite-iron nitrate intercalation compounds at first and then exfoliated them at $350^{\circ} \mathrm{C}$ or $900^{\circ} \mathrm{C}$. The EG contained iron phases such as $\alpha-\mathrm{Fe}, \alpha-\mathrm{Fe}_{2} \mathrm{O}_{3}, \mathrm{Fe}_{3} \mathrm{O}_{4}$, and $\mathrm{FeOOH}$. As noted in the discussion of Fig. 2, this EG retains its three-dimensional graphite structure and can behave as a host for intercalation compound formation. We therefore prepared a graphite-iron chloride intercalation compound and a EG -iron citrate mixture, and then reduced at $600^{\circ} \mathrm{C}$ in hydrogen atmosphere, where the starting EG was EG (T-1). The formation of $\alpha$-Fe during the reduction of both EG-iron citrate mixture and the graphite intercalation compound was confirmed by X-ray diffraction as shown in Fig. 10. The crystallite size calculated using the Debye-Scherrer equation was approximately $20-30 \mathrm{~nm}$ for both cases as shown in Table 3.

The SEM images of original EG and EG/iron hybrids are shown in Fig. 11. A large amount of iron particles were formed in the EG/iron hybrids derived from EG-iron chloride intercalation compounds. Magnetism measurements showed that both samples were superparamagnetic as seen from the magnetization curves shown in Fig. 12. The iron particle size was calculated according to equation (1), where $M_{\mathrm{H}}, M_{\mathrm{s}}, \mu, k_{\mathrm{B}}, \tau$ denote the magnetization at magnetic field $H$, saturation magnetization, magnetic moment, Boltzmann constant, relaxation time, respectively [30].

$$
M_{\mathrm{H}} / M_{\mathrm{s}}=\operatorname{coth}\left(\mu H / k_{\mathrm{B}} \tau\right)-k_{\mathrm{B}} \tau / \mu H
$$

The estimated size was approximately $1 \mu \mathrm{m}$ as shown in Table 4 . This result and the aforementioned SEM observation indicate that the reduction of the graphite-iron chloride intercalation compound is effective for the preparation of EG/iron hybrids. For the determination of the composition of this MEG (Magnetized EG), a fixed amount of MEG was placed in a quartz container and heat-treated at $750^{\circ} \mathrm{C}$ for 10 hours in air. The product was weighed and identified to be iron oxide $\left(\mathrm{Fe}_{2} \mathrm{O}_{3}\right)$ by X-Ray diffraction measurement. We adjusted the iron content by using the stoichiometry of the reaction of iron oxidation in air 
$\left(2 \mathrm{Fe}+3 / 2 \mathrm{O}_{2}--\mathrm{Fe}_{2} \mathrm{O}_{3}\right)$. This experiment showed that the present MEG is composed of 65 mass $\%$ carbon and 35 mass\% iron. The oil sorption experiment using $100 \mathrm{mg}$ of this MEG was carried out for $1 \mathrm{~L}$ of the engine oil-water emulsion with the concentration of $100 \mathrm{mg} / \mathrm{L}$. The concentration of engine oil after $60 \mathrm{~min}$ of sorption reached $3 \mathrm{mg} / \mathrm{L}$, which was higher than the corresponding value of $0.7 \mathrm{mg} / \mathrm{L}$ for EG. The difference can be partly attributable to the difference of actual quantity of EG; the former contains $65 \%$ of EG compared to the latter. Therefore, it can be said that the effect of iron in EG on its oil sorption capacity is considered to be small.

The magnetized EG (derived from the iron chloride intercalation compound) in the engine oil-water emulsion can be separated by applying an external magnetic field using a permanent magnet (Fig. S3). The efficiency of collecting EG loaded with oil seemed well at first glance. However, this should be confirmed quantitatively in future work, together with the reusability of MEG.

\section{Conclusions}

This paper investigated the oil-sorption behavior of EG for engine oil-water emulsion for practical application in the produced water treatment. Since it has been pointed out that EG has high capability of pure oil sorption, EG can be expected to be used also for oil-water emulsion. However, it has not yet been practically confirmed. Here we focused how much EG can reduce the oil content of emulsion with initial concentration of $10 \sim 200 \mathrm{mg} / \mathrm{L}$. We used engine oil-water emulsion as a model of produced water. We showed that $100 \mathrm{mg} / \mathrm{L}$ of oil in the emulsion of engine oil-water emulsion can be reduced to a concentration of 0.1 -few $\mathrm{mg} / \mathrm{L}$ using $\mathrm{EG}$ subjected to an additional oxidation treatment. Although EG also sorbs water, it sorbs oil preferentially; the oil concentration in the sorbed phase in EG was estimated to be at least 200 times that of the untreated emulsion $(200 \mathrm{mg} / \mathrm{L})$. This demonstrates that the EG reduces oil concentration in emulsion, in addition to the high sorption ability for pure oil. The strong 
interaction between n-Hexane molecules (non-polar aliphatic molecule as oil molecule model) and a graphene plane surface (EG) due to van der Waals interaction was demonstrated by the ab-initio relaxation calculation and classical MD simulation. A superparamagnetic character was observed for EG modified with iron particles, which enables the use of magnetic fields for recovering EG particles loaded with oil from treated emulsion. The oil concentration in treated water was reduced to a level comparable to water which can be treated by an NF or RO membrane treatment. The practical treatment of produced water with EG can be expected to provide environmental protection against the increasing amounts of produced water. EG, which is produced by treating natural graphite with sulfuric or nitric acid to form intercalation compounds and then washed with water and heated to foam, is inexpensive and is obtained from graphite, an abundant natural resource. We concluded that EG effectively removes oil during the treatment of emulsion, and in the future, we will conduct further studies toward its effective practical application using simulated and/or actual produced water.

\section{Acknowledgements}

This work was supported by the Center of Innovation Program (COI) from Japan Science and Technology Agency, JST. Also, he authors wish to thank Prof. Xiaoxi Liu of Shinshu Univ. for his fruitful discussions.

\section{References}

[1] Japan Oil, Gas and Metals National Corporation, Trend Survey on Produced Water Treatment in Oil and Gas Fields, OTM Consulting Ltd., 2011.

[2] Isogami H. et al., , Flocculation-magnetic separation system, Patent(US20120043264 A1), 2011.

[3] H.Hu, Z.Zhao, Y. Gogotsi, J.Qiu, Compressible carbon nanotube-graphene hybrid aerogels with superhydrophobicity and superoleophilicity for oil sorption, Environmental Science and 
Technology Letters 1 (2014) 214-220.

[4] Y.Zeng, K.Wang, J.Yao, H.Wang, Hollow carbon beads fabricated by phase inversion method for efficient oil sorption, CARBON 69 (2014) 25-31.

[5] B.Wang, R.Karthikeyan, X-Y.Lu, J.Xuan, M.K.H.Leung, Hollow carbon fibers derived from natural cotton as effective sorbents for oil spill cleanup, Ind. Eng. Chem. Res. 52 (2013) 18251-18261.

[6] X.Gui, Z.Zeng, Z.Lin, Q.Gan, R.Xiang, Y.Zhu, A.Gao, Z.Tang, Magnetic and highly recyclable macroporous carbon nanotubes for spilled oil sorption and separation, Applied Materials and Interfaces 5 (2013) 5845-5850.

[7] M.Z.Iqbal, A A.Abdala, Oil spill cleanup using graphene, Environ. Sci. Pollut. Res. 20 (2013) 3271-3279.

[8] B.Zhao, L.Zhang, Y.Liang, H.Qin, J.Yang, Efficient growth of millimeter-long few-walled carbon nanotube forests and their oil sorption. Appl. Phys. A 108 (2012) 351-355.

[9] Z.Fan, J.Yan, G.Ning, T.Wei, W.Qian, S.Zahng, C.Zeng, Q.Zhang, F.Wei, Oil sorption and recovery by using vertically aligned carbon nanotubes, CARBON 48 (2010) 4197-4214.

[10] Y.Pan, W.Wang, T.Wang, P.Yao, Fabrication of carbon membrane and microfiltration of oil-in-water emulsion: An investigation on fouling mechanisms, Separation and Purification Technology 57 (2007) 388-393.

[11] M.Toyoda, M.Inagaki, 2000, Heavy oil sorption using exfoliated graphite New application of exfoliated graphite to protect heavy oil pollution, CARBON 38 (2000) 199-210.

[12] M.Toyoda, K.Moriya, J.Aizawa, H.Konno, M.nagaki, Sorption and recovery of heavy oils by using exfoliated graphite Part1: Maximum sorption capacity, DESALINATION 128 (2000) 205-211.

[13] M.Inagaki, M.Toyoda, N.Iwashita, Nishi, Y., Koono, H., Exfoliated graphite for spilled heavy oil recovery, Carbon Science 2 (2001) 1-8.

[14] M.Toyoda, Y.Nishi, N.Iwashita, M.Inagaki, Sorption and recovery of heavy oils using 
exfoliated graphite Part4: Discussion of high oil sorption of exfoliated graphite, DESALINATION 151 (2002) 139-144.

[15] M.Inagaki, M.Toyoda, N.Iwashita, Y.Nishi, H.Koono, J,Fujita, T.Kihara, Sorption recovery and recycle of spilled heavy oils using carbon materials, TANSO 201 (2002) 16-23.

[16] Y-P.Zheng, , H-N.Wang, F-Y.Kang, L-N.Wang, M.Inagaki, Sorption capacity of exfoliated graphite for oils-sorption in and among worm-like particles, CARBON 42 (2004) 2603-2607.

[17] N.Sykam, K.K.Kar, Rapid synthesis of exfoliated graphite by microwave irradiation and oil sorption studies, Materials Letters 117 (2014) 150-152.

[18] M.S.Dresselhaus, M.Endo, Graphite, Intercalation Compounds Vol. II. Intercalation of Graphite Fibers, Springer-Verlag, Berlin Heidelberg, 1992, pp.347-411.

[19] M.A.Hubbe, O.J.Rojas, M.Fingas, B.S.Gupta, Cellulosic substances for removal of pollutants from aqueous systems, BioResources 8 (2013) 3038-3097.

[20] D.Mysore, T.Viraraghavan, Y-C.N Ji, Treatment of oily waters using vermiculite, Water Research 39 (2005) 2643-2653.

[21] A.M.Faraq and D.D.Harper, A review of environmental impacts of salts from produced waters on aquatic resources, Int. J. Coal Geology 126 (2014) 157-161.

[22] M. Valiev, E.J. Bylaska, N. Govind, K. Kowalski, T.P. Straatsma, H.J.J. van Dam, D. Wang, J. Nieplocha, E. Apra, T.L. Windus, W.A. de Jong, NWChem: a comprehensive and scalable open-source solution for large scale molecular simulations, Computer Physics Communications 181 (2010) 1477-1489.

[23] P. Giannozzi, S. Baroni, N. Bonini, M. Calandra, R. Car, C. Cavazzoni, D. Ceresoli, G. L. Chiarotti, M. Cococcioni, I. Dabo, A. Dal Corso, S. Fabris, G. Fratesi, S. de Gironcoli, R. Gebauer, U. Gerstmann, C. Gougoussis, A. Kokalj, M. Lazzeri, L. Martin-Samos, N. Marzari, F. Mauri, R. Mazzarello, S. Paolini, A. Pasquarello, L. Paulatto, C. Sbraccia, S. Scandolo, G. Sclauzero, A. P. Seitsonen, A. Smogunov, P. Umari, R. M. Wentzcovitch. QUANTUM ESPRESSO: a modular and open-source 
software project for quantum simulations of materials, Journal of Physics, Condensed Matter., 21 (2009) 395502.

[24] Wendy D. Cornell, Piotr Cieplak, Christopher I. Bayly, Ian R. Gould, Kenneth M. Merz, Jr., David M. Ferguson, David C. Spellmeyer, Thomas Fox, James W. Caldwell, and Peter A. Kollman, A Second Generation Force Field for the Simulation of Proteins, Nucleic Acids and Organic Molecules, Journal of the American Chemical Society 117 (1995) 5179-5197.

[25] W. Smith, I. T. Todorov, A short description of DL_POLY. Molecular Simulation 32 (2006) 935-943.

[26] M.A.Luftfullin, , O.N.Shornikova, A.V.Vasiliev, K.V.Pokholok, V.A.Osadchaya, M.I., Saidaminov, N.E.Sorokina, V.V.Avdeev, Petroleum products and water sorption by expanded graphite enhanced with magnetic iron phases, CARBON 66 (2014) 417-425.

[27] X.Din, R.Wang, X.Zhang, Y.Zhang, S.Deng, F.Shen, X.Zhang, H.Xiao, L.Wang, A new magnetic expanded graphite for removal of oil leakage, Marine Pollution Bulletin 81 (2014) 185-190.

[28] G.Wang, Q.Sun, Y.Zhang, J.Fan, L.Ma, Sorption and regeneration of magnetic exfoliated graphite as a new sorbent for oil pollution, Desalination 263 (2010) 183-188.

[29] H.Konnno, Y.Takahashi, H.Habazaki, Formation of iron dispersed graphite composites utilizing graphite and magnetic properties, TANSO 214 (2004) 191-193.

[30] A. Amikam, Introduction to the theory of ferromagnetism, Oxford Scientific Publications, 2001, p.84. 
Table 1. Oil type, its concentrations used and amount of oil-absorbing EG added.

\begin{tabular}{lcc}
\hline Oil & Oil concentration in emulsion $(\mathrm{ppm})$ & Amount of EG added (mg) \\
\hline Engine oil (synthetic oil) & 100,200 & $10,50,100,150,200$ \\
Engine oil (mineral oil) & 100 & 100 \\
\hline
\end{tabular}


Table 2. Properties of oil-absorbing samples used in the experiments.

\begin{tabular}{lccc}
\hline Sample & Apparent density $\left(\mathrm{gcm}^{-3}\right)$ & Specific surface area $\left(\mathrm{m}^{2} \mathrm{~g}^{-1}\right)$ & Sample shape \\
\hline T-1 & 0.007 & 49.7 & Foam \\
C-1 & 0.005 & 29.8 & Foam \\
C-2 & 0.009 & 28.4 & Foam \\
C-3 & 0.017 & 24.4 & Foam \\
TO-1 & 0.006 & 43.5 & Foam \\
Palm shell activated carbon & 2.04 & 1176.1 & Particle \\
Vermiculite & 0.172 & 6.8 & Particle \\
\hline
\end{tabular}


Table 3. Crystallite size calculated from Scherrer equation.

\begin{tabular}{cc}
\hline Starting material & Crystallite size $\alpha-\mathrm{Fe} 110(\mathrm{~nm})$ \\
\hline EG-iron chloride (GIC) & 30.0 \\
EG-iron citrate (mixture) & 26.2 \\
\hline
\end{tabular}

*Scherrer equation: $\tau=K \lambda / \beta \cos \theta, K=1.0$ 
Table 4. Iron particle sizes estimated from equation (1).

\begin{tabular}{ccccc}
\hline Starting material & H/Oe (I: 0.5) & H/Oe (I: 0.8) & Diameter (I: 0.5) & Diameter (I: 0.8) \\
\hline iron chloride & 1451 & 3399 & $1.07 \mu \mathrm{m}$ & $1.12 \mu \mathrm{m}$ \\
iron citrate & 2349 & 4398 & $0.95 \mu \mathrm{m}$ & $1.05 \mu \mathrm{m}$ \\
\hline
\end{tabular}

*I: Normalized M 

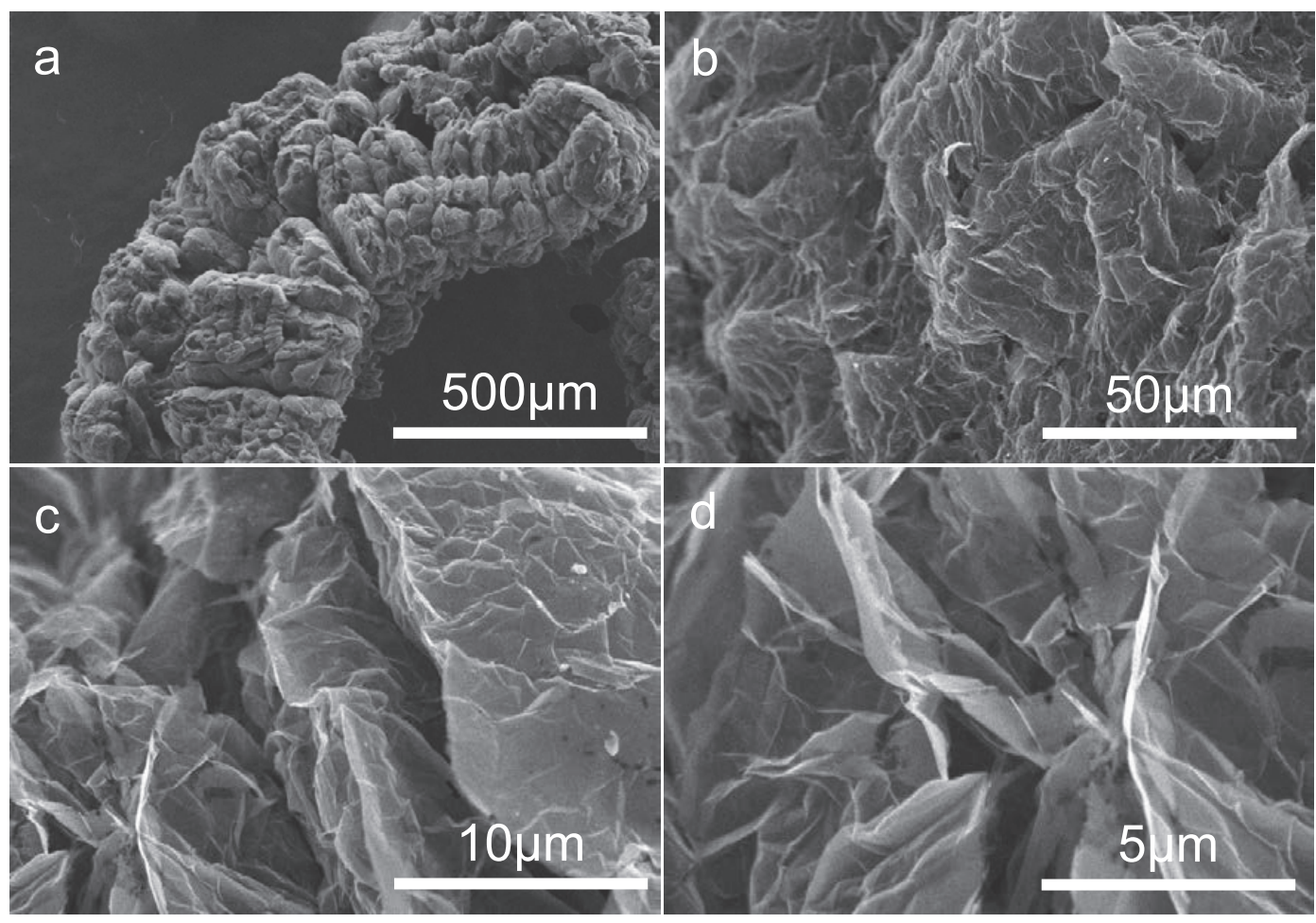

Fig. 1. SEM images of the original EG (T1) with different magnifications: (a) x100, (b) x1,000, (c) $\times 5,000$ and (d) $\times 10,000$. 


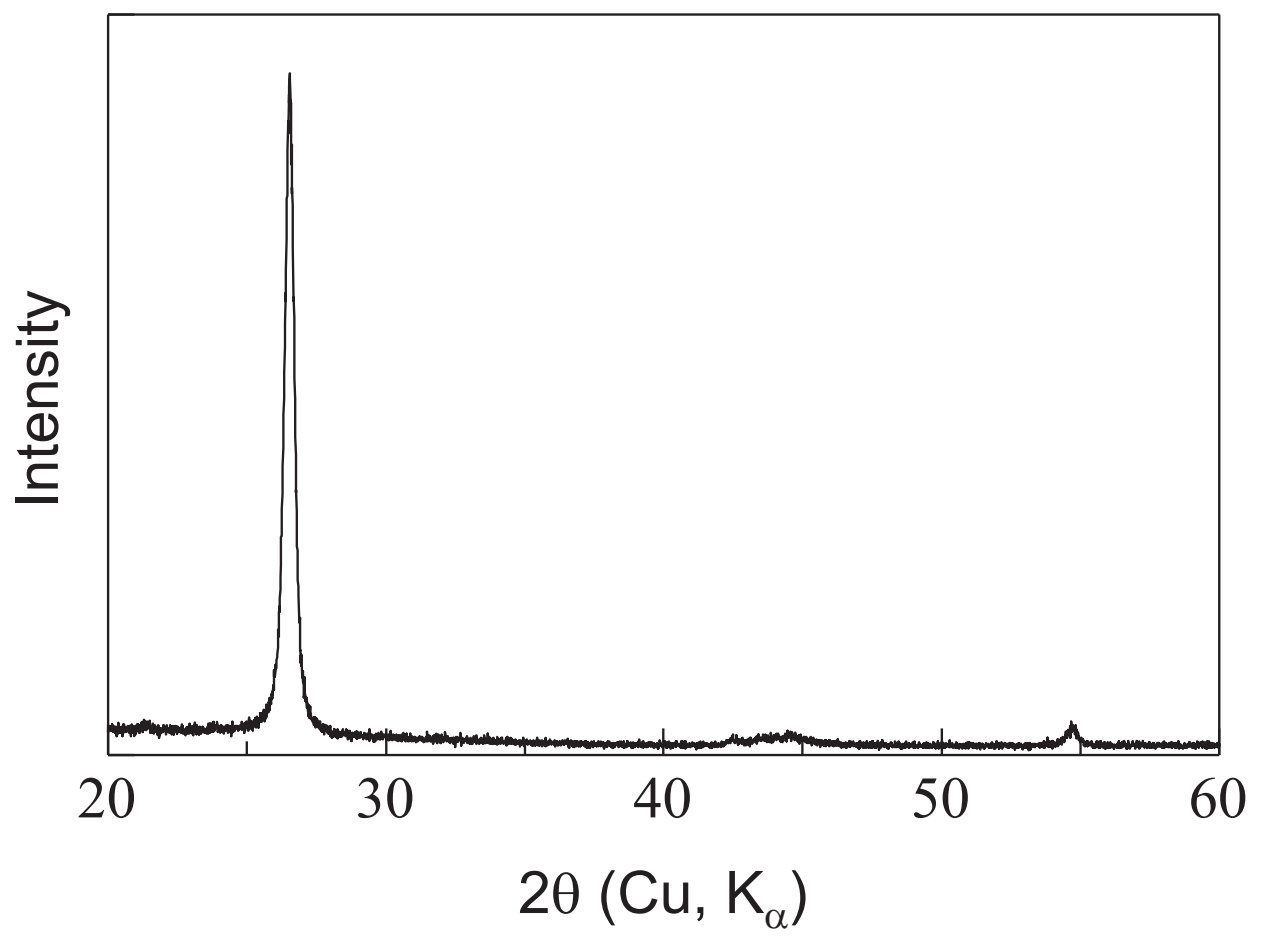

Fig. 2. X-ray diffractogram of the EG sample (T-1). 


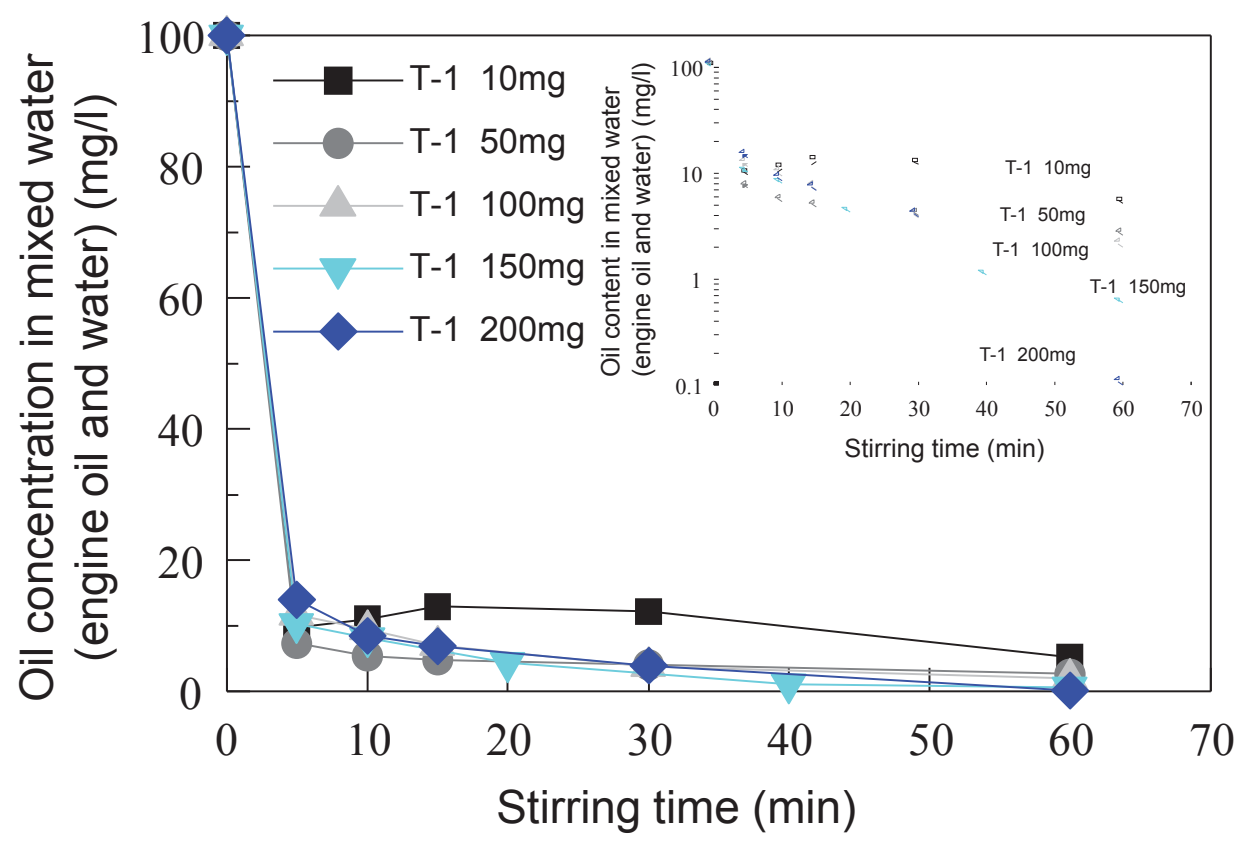

Fig. 3. Change of oil concentration as a function of time when EG (T-1) was added in simulated engine oil-water emulsion (oil; synthetic oil, $100 \mathrm{ppm}$ ). The insert shows a plot of the logarithmic value of oil content vs. time. 


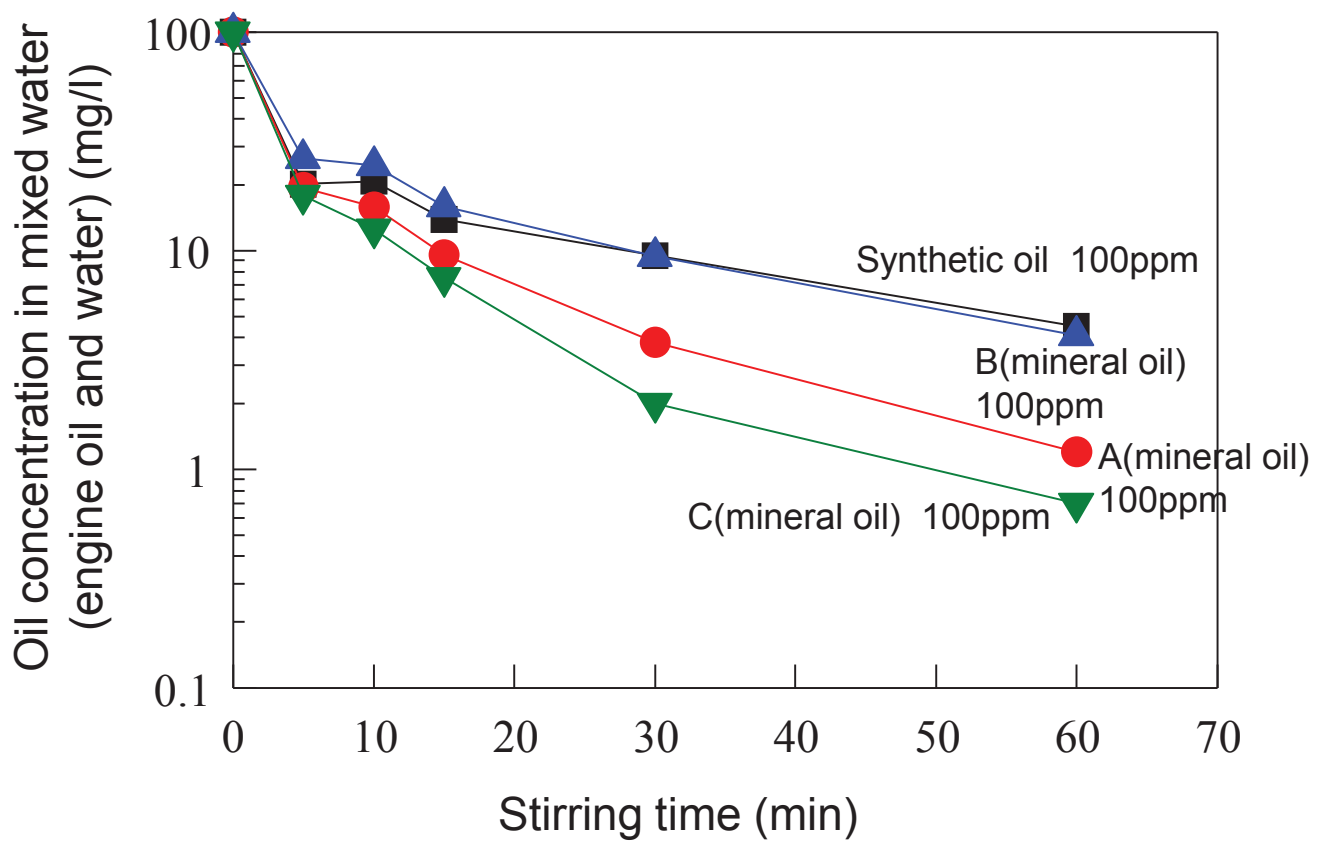

Fig. 4. Sorption properties of EG (T-1) with different types of engine oil (synthetic oil and mineral oil). 


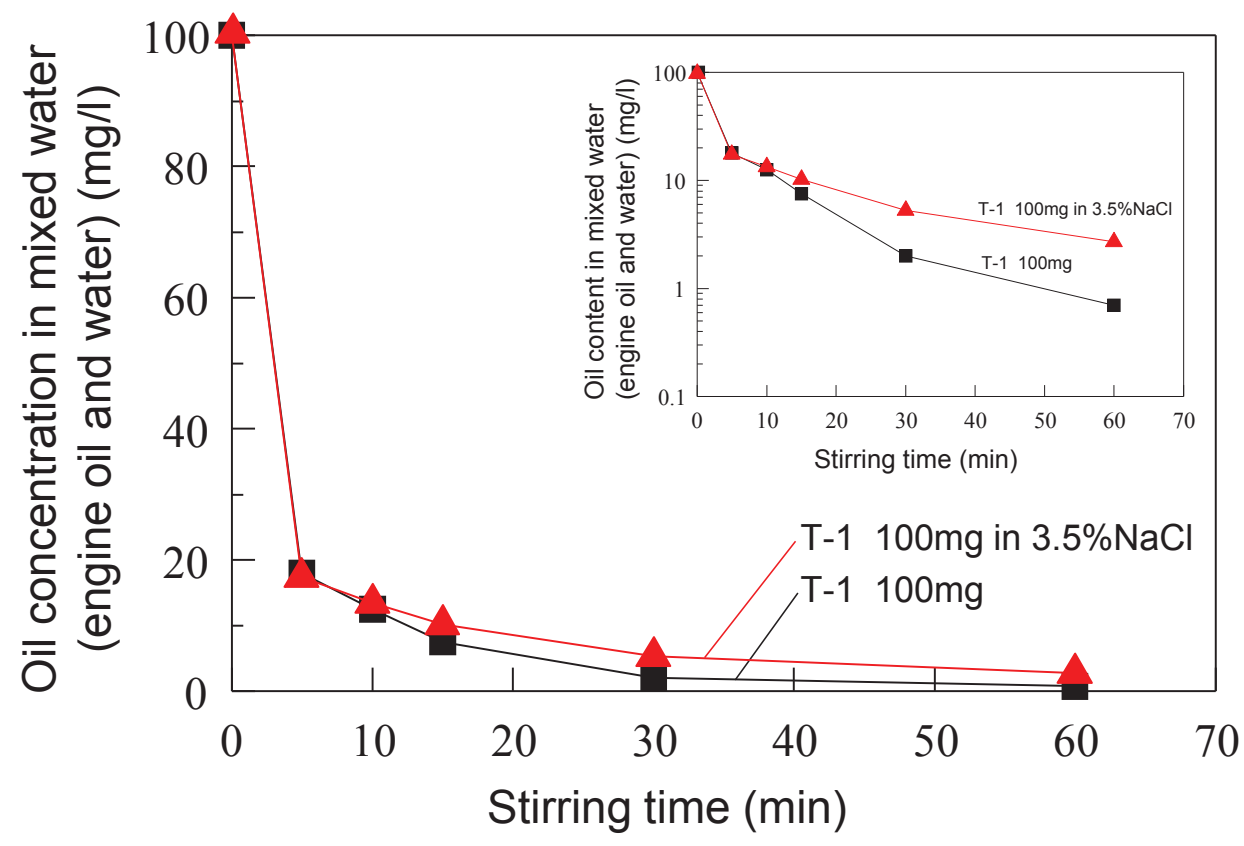

Fig. 5. Oil-sorbing function of EG in salt-water-based engine oil-water emulsion (mineral oil C). The inset shows a plot of the logarithmic value of oil content vs. time. 


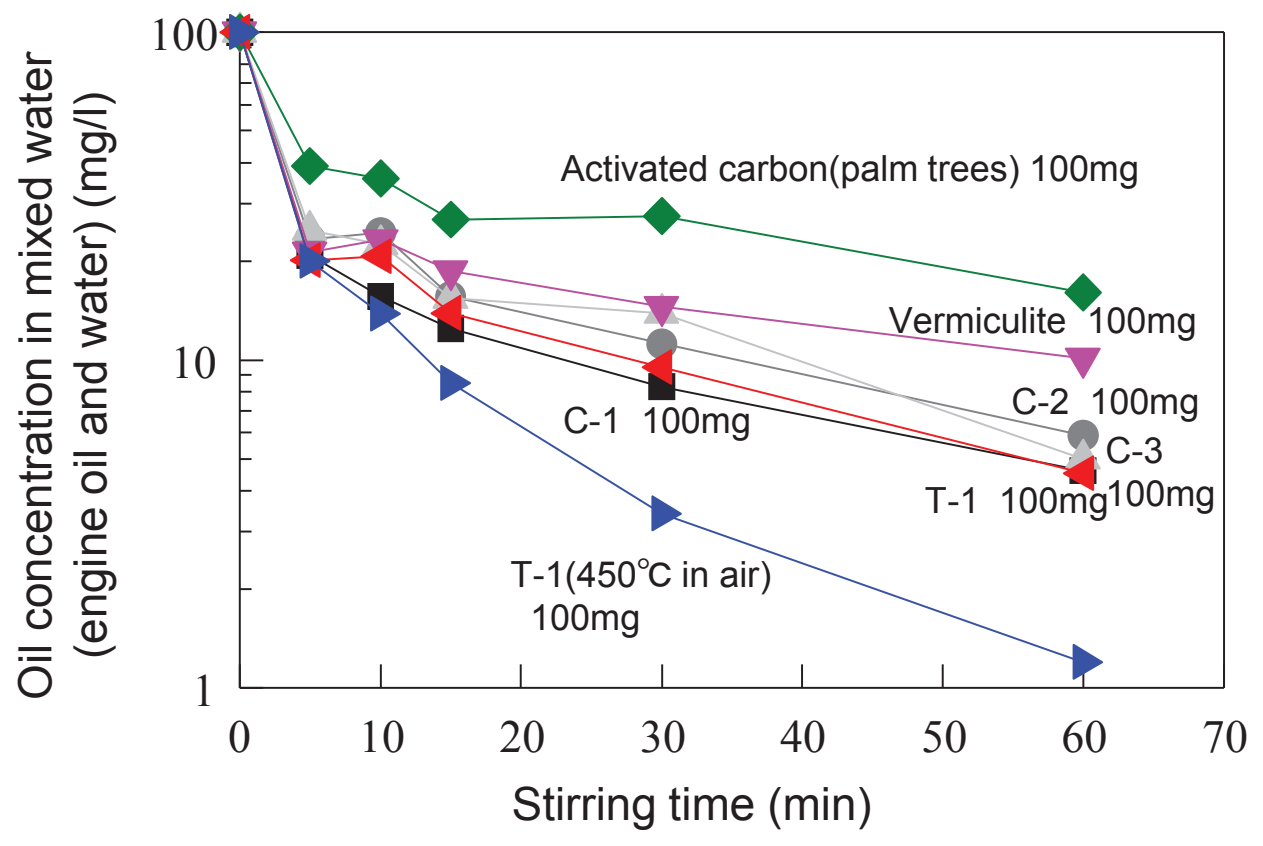

Fig. 6. Comparison of oil-absorbing properties of the investigated materials in engine oil-water emulsion (synthetic oil, 100 ppm). 

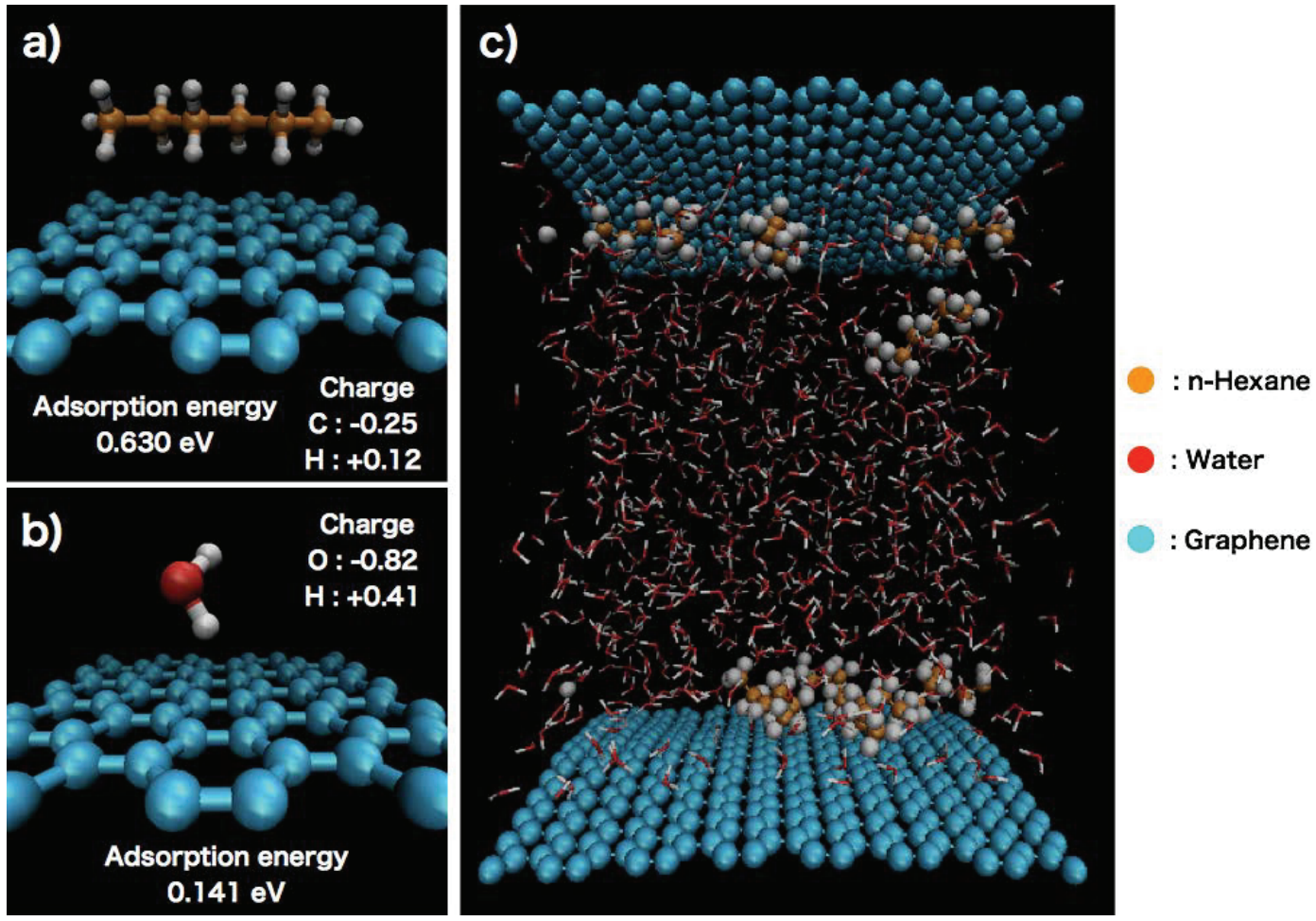

Fig. 7. a) Adsorption energy calculations of n-Hexane on graphene. Atomic charge value represents the average value. b) Water molecule adsorption on graphene and its energy. c) MD snapshot of nine n-Hexane, in 900 water molecule, red and white atoms, system with water/graphene interface. 


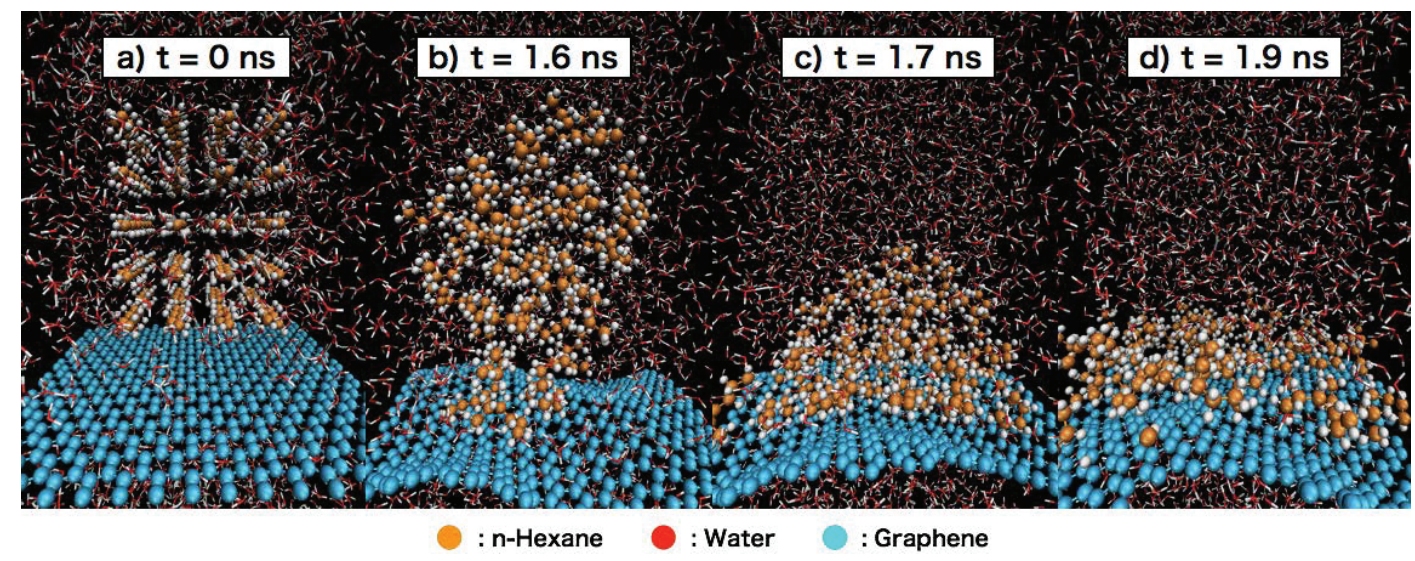

Fig. 8. MD snapshots of $\mathrm{n}$-Hexane droplet adsorption and spreading process on graphene. a) Initial conditions b) n-Hexane droplet contacts the graphene surface. c) Snapshot of the spreading of $n$-hexane on the graphene surface. d) Minimized energy state. 


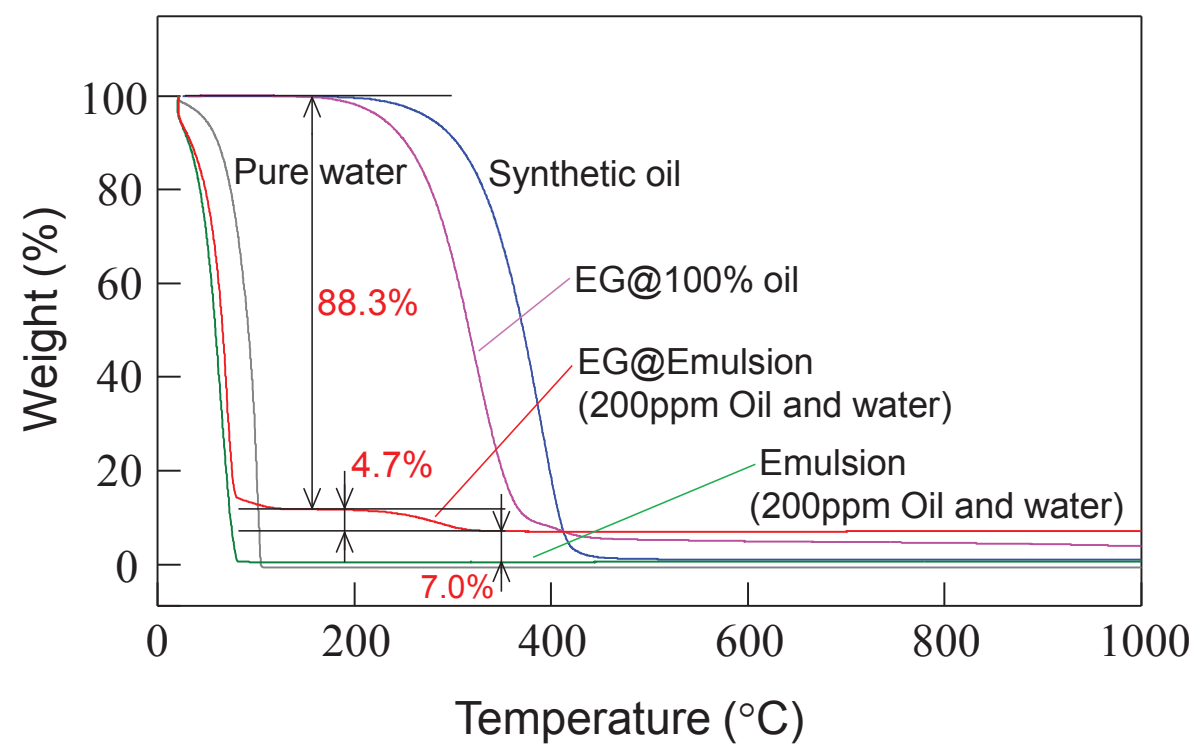

Fig. 9. TG weight change of EG after sorption of engine oil-water emulsion (synthetic oil, 200 ppm) and oil. 


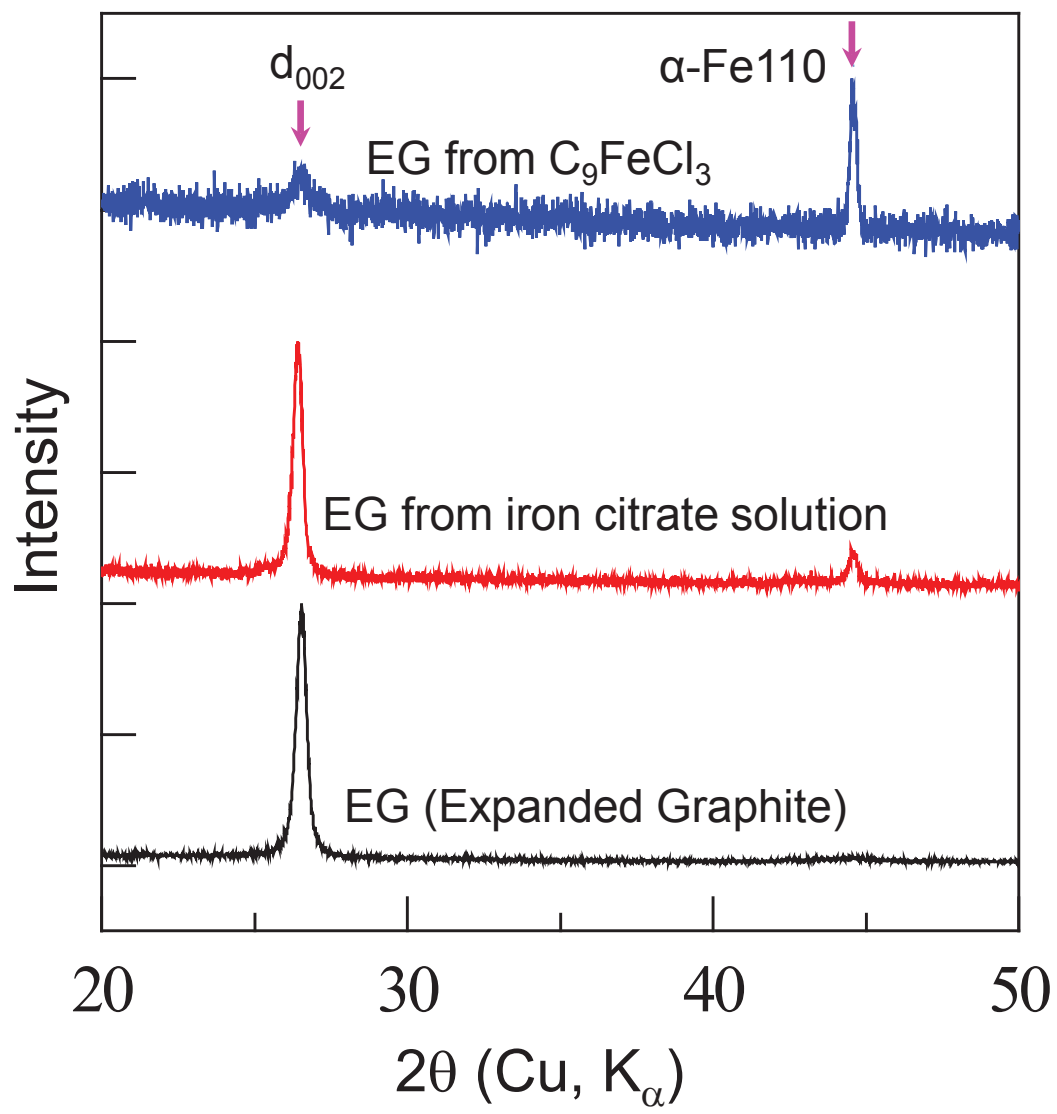

Fig. 10. X-ray diffractograms of (a) original EG, (b) EG/iron hybrid prepared from EG/iron citrate mixture and (c) EG/iron hybrid prepared from EG-iron chloride intercalation compounds. 


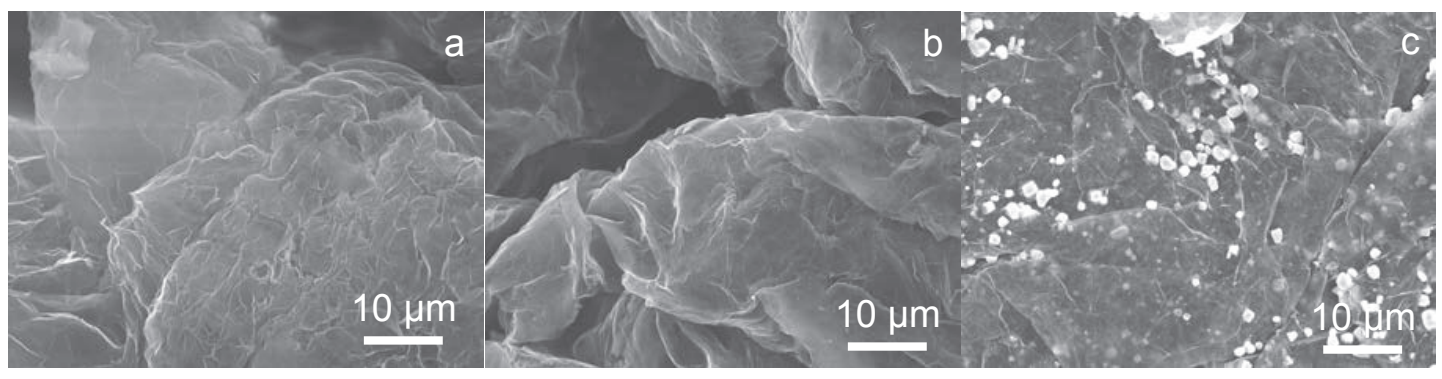

Fig. 11. SEM images of (a) original EG, (b) EG/iron hybrid prepared from EG/iron citrate mixture and (c) EG/iron hybrid prepared from intercalation compounds of EG-iron chloride. 

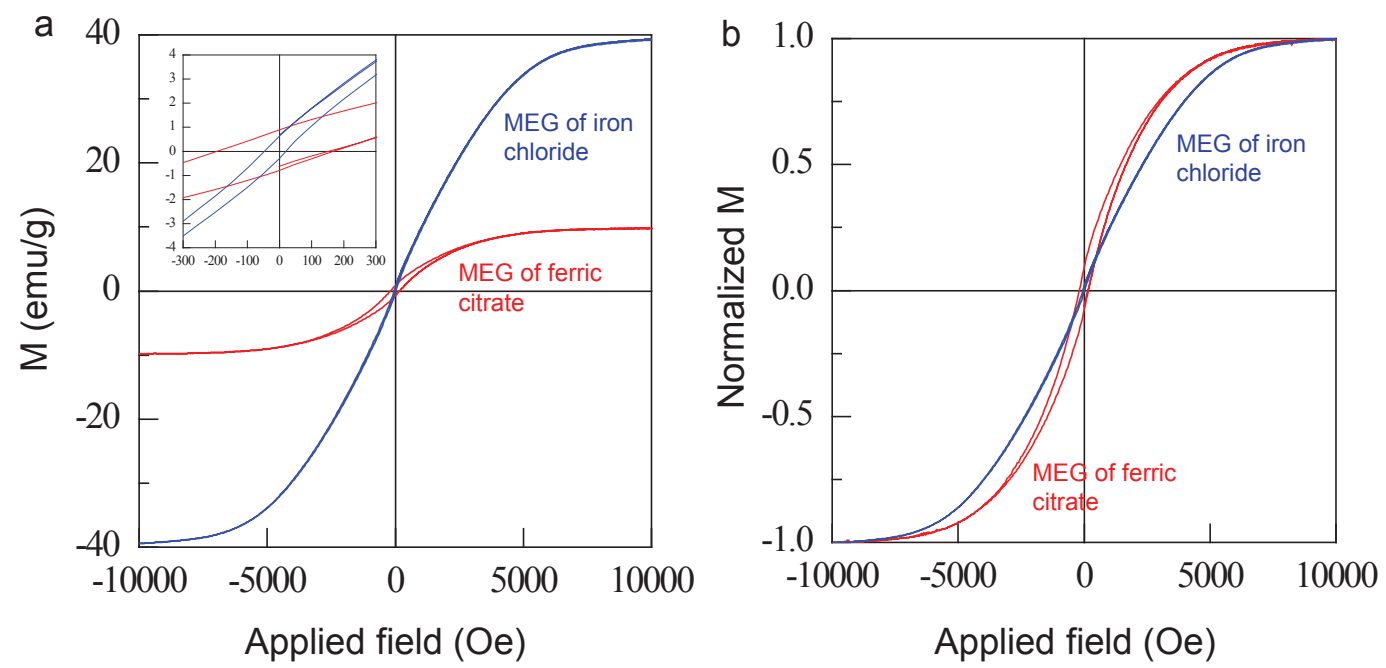

Fig. 12. (a) Magnetization hysteresis curves of two kinds of EG/iron hybrids plotted as a function of magnetic field strength (the inset shows the plots in the vicinity of zero field) and (b) normalized magnetization hysteresis vs. magnetic field strength plot. 